\title{
Correction of Angular Deformities by Physeal Distraction
}

Jose Cañadell, M.D., and Julio De Pablos, M.D.

From the Department of Orthopaedic Surgery and Traumatology, Faculty of Medicine, University of Navarra, 31008 Pamplona, Spain.

Reprint requests to Julio de Pablos, M.D.

Orthopaedics, University of Navarra Medical School

Apdo. 192, 31080, Pamplona, Spain.

\begin{abstract}
Physeal distraction is an alternative to more conventional treatments for the correction of angular deformities of the long bones. Twenty deformities of the femur and tibia, vine of which also involved associated shortening, were partially or completely corrected. In eight cases, there was physeal bony bridge. Complete correction of the angular deformity was achieved in 17 patients, and in seven patients, more than $80 \%$ correction was achieved. There were complications in four patients that hindered complete correction of the deformity, or shortening, or both. The external control of the correction until consolidation occurs is progressive and fairly noninvasive. The method allows external control of the correction until consolidation; it acts at the site of the deformity itself and permits lengthening and angular correction during therapy. In deformities with a physeal bony bridge, correction can be achieved with physeal distraction alone, prior resection of the bridge is not unnecessary. The technique is indicated in cases of angular deformities in patients nearing skeletal maturity and particularly in subjects in whom there is associated shortening.
\end{abstract}

\section{INTRODUCTION}

Physeal distraction is a technique for progressively lengthening bone, but is applicable only in patients who have not reached maturity. It is based on use of the growth plate (physis) as the "locus minoris resistentiae" of the bone, through which —by distraction of both sides - separation of the metaphysis and epiphysis is achieved and, hence, lengthening of the bone. It is therefore a technique that does not require osteotomy or osteoclasia - "bloodless" lengthening — unlike other techniques that do require such procedures. ${ }^{9}$

The first experiments based on these ideas were performed in animals by Ring $^{18}$ in 1958, and the first clinical applications of the technique were published in Russia by Zavijalov and Plaskin in $1967^{21}$ and 1968, ${ }^{22}$ and Ilizarov and Soybelman in 1969, ${ }^{9}$ with promising results. In Western Europe, it was Monticelli and Spinelli ${ }^{12}$ who began applying physeal distraction in clinical practice. 
The technique, originally conceived for the purpose of simple lengthening of the bones, is also applied currently for correcting angular deformities in skeletally immature long bones. ${ }^{4,5,13,15}$

The goal of the present work is to offer a review of the clinical experience with physeal distraction for the treatment of angular deformities of the long bones during the period from 1982 to 1989 and to offer what is believed to be some useful conclusions for future application.

\section{MATERIALS AND METHODS}

At the authors' institution from 1982 until 1989, physeal distraction had been applied on 65 occasions. In 45 of these cases, the objective was to perform a simple lengthening; in the other 20, the method was essentially used to correct angular deformities of the ends of long bones.

The latter group comprised 17 patients (in three there were double affectations), 11 boys and six girls, with ages ranging from 11 to 14.5 years at the beginning of corrective treatment. Follow-up periods ranged from a minimum of 11 months in the postoperative period to a maximum of 54 months. In the Iast roentgenographic controls performed, ten of the 17 patients studied had reached skeletal maturity.

In 12 of the 20 deformities, the growth plate at the level of the deformity did not show radiologic signs of premature closure, whereas in the remaining eight, the radiologic imagen disclosed a bony bridge across the physis.

Of the 12 angular deformities with no bony bridge (ten patients), the location was at the distal end of the femur in seven (six valgus and one varus), on the proximal end of the tibia in two (two varus), and on the distal end of the tibia in three (two valgus, two varus). The etiology of the deformities were as follows: congenital in three femur valgus and one distal tibia varus; posttraumatic in one femur valgus and one distal tibia varus; a burn in one femur valgus; idiopathic in one bilateral femur valgus and one bilateral proximal tibia varus; and the sequela of an already-consolidated congenital tibia pseudoarthrosis in one distal tibia valgus. Apart from the angular deformity, in this group there was a significant degree of associated shortening (more than $1.5 \mathrm{~cm}$ ) in six of the 12 deformities.

Of the eight angular deformities with bony bridge (seven patients), the location was on the distal end of the femur in three patients (two valgus and one varus), on the proximal tibia in three patients (three varus), and on the distal tibia in two patients (one valgus, one varus). In one patient of this group, the affectation was bifocal on the distal femur and the proximal tibia. The etiology of the deformity was posttraumatic in one femur varus, one proximal tibia varus, and one distal tibia valgus; after an episode of meningitis caused by Meningococcus in one femur valgus, two proximal tibia varus, and one distal tibia varus; and after an episode of arthritis in the knee due to Staphylococcus in one femur valgus. In three of the eight deformities, the shortening of the angular deformity was more than $1.5 \mathrm{~cm}$.

\section{CORRECTIVE TREATMENT}

In all patients, corrective treatment of the deformities was performed by physeal distraction with external monolateral fixer-distractors. Specifically, the equipment used was the ball-joint model of the Dynamic Axial External Fixation (Orthofix, 
Verona, Italy) ${ }^{6}$ in eight patients and a modified Wagner apparatus (Houmedica, Geneva, Switzerland) in the remaining. The modification of the Wagner apparatus for physeal distraction consisted of substituting one of the conventional screw-holders by a "T"shaped piece that allowed insertion of the screws (epiphyseal and diaphyseal) on perpendicular planes (Fig. 1).

The surgical procedure was the same in all cases and consisted of the emplacement of the distractor apparatus with two or three screws inserted into the diaphysis perpendicular to its longitudinal axis and two, or possibly three, screws inserted into the epiphysis parallel to the articular surface of the corresponding bone. Attempts were also made to achieve a maximum parallelism of the longitudinal axis of the body of the apparatus with respect to the axis of the bone shaft. Where there was a physeal bony bridge, this was not resected in any patient. Distraction was routinely begun at 24 hours after the operation. Two different strategies were employed in the corrective process. In the first (Strategy I), used in seven deformities, asymmetric distraction of the physis was begun from the very start of treatment in such a way that a progressive correction of the angular deformity was achieved. In both pieces of apparatus, this was attained by a simple free-moving hinge system on the end of the apparatus most proximal to the deformity, causing the longitudinal distraction applied to the apparatus to become converted into angular movement of the epiphyseal screws, thus achieving a progressive correction of the deformity. The rate of distraction applied to the apparatus during this process of progressive angular correction was 1.5 ( $2 \times 0.75) \mathrm{mm} /$ day. Once this had been performed, in the patients in which there was associated shortening, the movement of the hinge was blocked and symmetric physeal distraction continued at a rate of $1(2 \times 0.5) \mathrm{mm} /$ day until the dismetria had been corrected (Fig. 2).

The second method (Strategy II), used in the remaining 13 deformities, consisted of an initial longitudinal distraction, with blocking of angular movement, until a sufficient degree of lengthening had been obtained to permit angular correction in a single step. Immediately thereafter, the angular movements of the apparatus were blocked and if there was associated shortening, symmetric distraction was initiated until, at least ideally, the dismetria had been corrected. In this second method, the rate of distraction applied to the apparatus was always 1 ( $2 \times 0.5) \mathrm{mm} /$ day (Fig. 3 ).

In all the tibial angular deformities accompanied by shortening and in one case of isolated tibial deformity, osteotomy of the fibula was performed in association with the distraction. In all these cases, distal tibial—fibular stabilization was performed either with emplacement of a conventional 4.5-mm screw into the bone cortex or with one of the screws of the fixer placed in the distal tibial epiphysis.

From eight to ten days after the operation, no restrictions were placed on the amount of load put on the surgically treated limb by the patients; however, they were not required to load more than was comfortable for them.

In all patients, the clinical and radiologic evolution of the patients were evaluated at weekly intervals during the first months and, thereafter, every two weeks in the later phases of treatment.

Throughout the time during which the apparatus was in place, the patient was encouraged to actively move his or her joints adjacent to the lengthened segment as much as possible. After removing the apparatus, when necessary, a specialized physiotherapy program was initiated.

Except in the patients in which it was imperative to discontinue treatment with the apparatus for one reason or another, its removal was empirically based on the follow-up roentgenographs. 


\section{RESULTS}

Initially, correction of the angular deformity was possible in the patients studied with one exception irrespective of the presence or not of a physeal bony bridge at the level of the deformity (Figs. 4 and 5). On another two occasions, there was a partial loss of the correction achieved after removing the apparatus; this was compensated by the application of plaster casts until definitive consolidation. The remaining corrections persisted satisfactorily after removal of the apparatus. Neither were any recurrentes in the corrected deformities observed once the zone of distraction had consolidated. Grading of the corrected deformities ranged between a maximum of $32^{\circ}$ in one case of proximal tibia varus with a physeal bony bridge in a patient who had suffered from sepsis caused by Meningococcus in infancy, to a minimum of $16^{\circ}$ in a distal femur varus $\left(10^{\circ}\right.$ excess) of congenital etiology.

Regarding the extent of premature partial physeal closure in the eight deformities in which this occurred, in no case did this exceed more than $50 \%$ of the whole of the affected physis.

In all the cases with shortening associated with the deformity, apart from correcting the angular deformity, attempts were also made to correct the dismetria, at least partially. The maximum lengthening achieved in this group of patients (vine) was $9 \mathrm{~cm}$ in a congenital femoral shortening of $18 \mathrm{~cm}$ with distal valgus. The minimum lengthening achieved was $2.5 \mathrm{~cm}$ in a case of femoral shortening with associated distal valgus. Of the vine shortenings, complete correction of the dismetria was obtained in five, the correction was almost complete in two, and there was no correction in two. In two patients, lengthening had to be interrupted prematurely be-cause of a complication, not reaching the above-mentioned $80 \%$.

Consolidation periods varied considerably and were directly related to the degree of angular correction and lengthening required. Specifically, the maximum was 9.2 months in the case of the above maximum lengthening, and the minimum was 2.5 months in a case of a $16^{\circ}$ bilateral proximal tibia varus of idiopathic origin.

In all cases, consolidation in the distraction zone was achieved without the need for support in the form of bone graft or internal implants for internal fixation. With the exception of two cases on the distal end of the femur, two in the proximal tibia, and one in the distal tibia, it was not necessary to apply plaster bandages to protect the bone after removing the apparatus in the rest of the deformities.

Regardless of the existence of physeal bony bridges, the patients did not complain of increased pain at the level of the distraction zone from two to three days after starting treatment.

A distinction can be made between those patients in the series with major complications and those with minor complications. Among the former, there was a case in which a dysfunction of the distractor apparatus occurred, which did not allow the authors to continue lengthening once the angular correction had been completed. There was one case of severe infection in the trajectory of the screws - thus making premature removal of the apparatus necessary - and two cases of partial loss of angular correction after removing the apparatus owing to insufficient consolidation of the distraction zone. These accounted for $20 \%$ of the major complications with respect to the total 20 deformities treated.

Among the minor complications, there were transient or unimportant pin-tract infections (14\% of the total of screws), which did not prevent treatment from being completed, and the transient joint stiffness observed on removing the distraction. The mentioned 
stiffness was particularly important in the knee after distal femoral distraction, but consistently disappeared after a few weeks, falling to normal ranges simply with physiotherapy.

Finally, after the corrective treatment, in all patients premature complete closure of the operated physis was observed with respect to the contralateral member. This did not lead to any significant loss either in correction or in lengthening in any of the cases.

More details on the patients, methods, and results are given in Table 1.

\section{DISCUSSION}

The treatments most frequently recommended for correction of angular deformities of the long bones of the skeleton are corrective osteotomies, ${ }^{19,20}$ partial physeal blockade by epiphysiodesis, ${ }^{17}$ or epiphyseal stapling. ${ }^{2}$

Single-step correction by osteotomy has the following drawbacks: it is difficult to perform, especially in important deformities; there is a frequent need for internal fixation, which involves a later surgical intervention for removal; and it is impossible to modify the correction achieved in the postoperative period. Additionally, if the osteotomy is the "closure" type, with resection of the bone wedge, a shortening of the corrected bone occurs. If, by contrast, it is the "opening" type, the risk of lesions by traction of the noble soft tissue increases and frequently it becomes necessary to graft bone to stabilize and facilitate consolidation at the level of the correction made.

Regarding partial blockades of the growth plate, the main limitations to this are the patient's age when applying them (maximum, 10-11 years); their low predictability, which has recently improved with the tables of Bowen et al.; ${ }^{3}$ and the fact that shortening of the bone may occur. Also, when there is a physeal bony bridge, the maximum benefit that can be derived from blockade of the growth plate is the halting of the progression of the deformity but not the correction. Specifically, in the case of this type of deformity with physeal bony bridges, Langenskiold ${ }^{10,11}$ proposed a treatment by resection of the bridge and the intercalation of different kinds of materials, in particular autogeneic fatty tissue.14,16 This method, which has been effective in many cases, is also limited by the age of the patient (10-11 years) and its difficult predictability.

The main advantages of physeal distraction applied to angular deformities in growing patients are essentially that one is dealing with a progressive method of correction. This means that correction and consolidation are facilitated without the need for bone grafting nor internal fixation and that the risks of sharp distractions decrease. Additionally, the method is fairly noninvasive; it permits external control of the correction until consolidation, it acts exactly at the site of the deformity, and-perhaps more importantly-it permits the orthopedist to perform lengthenings at the same time as the angular correction during the same period of therapy. In deformities with physeal bony bridges, another advantage of physeal distraction is that, if the bridge is not massive (50\% approximately), no surgical procedure is required to resect it, because, with simple distraction, it can be broken up. This is also the opinion of Connolly et al. ${ }^{5}$ as stated in a recent clinicoexperimental report.

Although some authors advocate other surgical interventions before physeal distraction, such as resection of the bridge accompanied by intercalation of autogeneic fatty tissue ${ }^{8}$ or osteotomy of the bridge, ${ }^{13}$ in the authors' experience, these were not necessary.

The main disadvantages of the method proposed are those of fixation-distraction, in general, and physeal distraction in particular. Among the latter, of special interest are possible lesions to the growth plate and also rigidity and articular infections. 
With respect to physeal viability after distraction in the cases currently discussed, evolution was very different, although in an experimental study with young sheep carried out at the authors' institution, ${ }^{7}$ a highly satisfactory evolution in normal physes subjected to slow distraction $(0.5 \mathrm{~mm} /$ day $)$ was observed. Premature closing in the growth plates in 20 deformities may have been caused by a previous lesion in the distracted physis and the $0.5 \mathrm{~mm} /$ day or greater distraction rate. This, together with the fact that in another experimental study' a constant recurrente of the bony bridge and deformity was observed when the method was applied to previously deformed femurs of skeletally immature sheep, means that the recommendation of physeal distraction in angular deformities - especially if there is a physeal bony bridge - should be limited to the period in which the skeletal age of the patients is as close as possible to maturity (ten to 11 years minimum).

The joint stiffness after treatment consistently disappeared when physiotherapy was started after removing the apparatus.

Although in this series of patients no case of septic arthritis was observed, there is a fairly high risk of this occurring, especially in cases of physeal distraction of the distal femur, such that extreme precautions should be taken.

Infections of the bone in the trajectories of the screws, a common problem in all types of external fixation-distraction, may become so important or aggressive, or both, that it may become necessary to interrupt treatment, although this does not happen often. Furthermore, it should be noted that it is even less common to find osteomyelitis caused by infection of the trajectories of the screws. At the authors' institution, including all the cases of external fixation-distraction, all infections disappeared after removing the screw corresponding to the infected trajectory, however serious they were.

Another drawback of the proposed treatment is that the patient is obliged to wear the apparatus for several months with the discomfort evidently inherent to this, especially if the apparatus is circular.

Concerning the actual corrective strategy to be used, the authors are not inclined to either, as the results with both were similar. However, it should be pointed out that with a well-placed monolateral fixer, Strategy I is only valid in cases of femoral valgus and tibial varus. By contrast, Strategy II can be applied for varus and valgus, regardless of whether there occur in the tibia or in the fe-mur. Another difference between the two strategies is that with Strategy I, mounting stability is better because the fragments of bone remain in contact during the angular correction, whereas in Strategy II, this is not the case. Accordingly, Strategy I is used in cases of femoral valgus, or tibial varus, or both, with or without associated shortening and Strategy II is used in the remaining cases. For the distraction phase in Strategy I, a lengthening rate was applied in the body of the apparatus of $1.5 \mathrm{~mm} /$ day in two increases of $0.75 \mathrm{~mm}$ each. This was because in the hypothetical situation of a distance of $15 \mathrm{~cm}$ between the centers of rotation of the epiphysis and the screw-holder clamp and an epiphyseal width of $8 \mathrm{~cm}, 1.5-\mathrm{cm}$ lengthening of the body of the apparatus produced an angular correction of $0.6 \%$ and a lengthening of the epiphyseal aspect closest to the fixator of approximately $0.8 \mathrm{~mm}$. When distraction is performed symmetrically, a rate of $1 \mathrm{~mm} /$ day is applied over two increments because this is the customary protocol in all types of bone lengthening.

In physeal distraction, particularly when this is performed with an elastic circular apparatus, the patient normally feels an intense pain in the area of distraction from two to three days after initiating treatment.' In patients in this series, this was not observed, perhaps due to the fact that because they were using distractors that were more rigid, the 
physeal fracture occurred in a more controlled and less brusque fashion, better tolerated by the patient.

In general, the results have been satisfactory, with the exception of the four cases in which there were major complications. However three of them could have been avoided. The two partial losses of angular correction were caused by premature removal of the apparatus, and a dysfunction in the distractor in the third patient could easily have been compensated had there been another available to replace it. In the fourth patient, the severe complication (infection) was unavoidable be-cause there is never any way of absolutely preventing such situations.

\section{REFERENCES}

1. Azcárate. J., de Pablos, J., and Cañadell, J.: Distracción fisaria en los cierres fisarios prematuros. Estudio experimental. Acta Ortop. Latinoamericana 15:71, 1988.

2. Blount, W. P., and Clark, G. R.: Control of bone growth by epiphyseal stapling. Preliminary report. J. Bone Joint Surg. 1949:31A:464.

3. Bowen, J. R., Leahey, J. L., Zhang, Z., and MacEwen, G. D.: Partial epiphysiodesis at the knee to correct angular deformity. Clin. Orthop. 198:184, 1985.

4. Cañadell, J., and de Pablos, J.: Breaking bony bridges by physeal distraction. A new approach. International Orthopedics (SICOT). 9:223, 1985.

5. Connolly, J. F., Huurman, W. W., Lipiello, L., and Pankaj, R.: Epiphyseal traction to correct acquired growth deformities. An animal and clinical investigation. Clin. Orthop. 202:258, 1986.

6. De Bastiani, G., Aldegheri, R., Renzi-Brivio, L., and Trivella, G. P.: Dynamic axial external fixation. Automedica 10:235, 1989.

7. De Pablos, J., and Cañadell, J.: Experimental physeal distraction in immature sheep. Clin. Orthop. 250:73, 1990.

8. Foster, B. K.. Rozenbilds, M., and Yates, R.: Further results of distraction physeolysis in a sheep tibial model. J. Bone Joint Surg. 68B:333, 1986.

9. Ilizarov, G. A., and Soybelman, L. M.: Some clinical and experimental data on the bloodless lengthening of the lower limbs. Exp. Khir. Anesth. 4:27, 1969.

10. Langenskiold, A.: The possibilities of eliminating premature partial closure of an epiphyseal plate caused by trauma or disease. Acta Orthop. Scand. 38:267, 1967.

11. Langenskiold, A.: Surgical treatment of partial closure of the growth plate. J. Pediatr. Orthop. 1:3, 1981.

12. Monticelli, G., and Spinelli, R.: Distraction epiphysiolysis as a method of limb lengthening. III. Clinical applications. Clin. Orthop. 154:274, 1981.

13. Monticelli, G., and Spinelli, R.: A new method of treating the advanced stages of tibia vara (Blount's disease). Ital. J. Orthop. Traumatol. 10:295, 1984.

14. Ogden, J. A.: The evaluation and treatment of partial physeal arrest. J. Bone Joint Surg. 69A:1297, 1987.

15. Peltonen, J., Karaharku, E., and Alitalo, J.: Experimental epiphyseal distraction producing and correcting angular deformities. J. Bone Joint Surg. 66B:598, 1984. 
16. Peterson, H. A.: Partial growth plate arrest and its treatment. J. Pediatr. Orthop. 4:246, 1984.

17. Phemister, D. B.: Operative arrestment of longitudinal growth of bones in the treatment of deformities. J. Bone Joint Surg. 15:1, 1933.

18. Ring, P. A.: Experimental bone-lengthening by epiphyseal distraction. Br. J. Surg. 49:169, 1958.

19. Sasaki, T., Yagi, T., Monji, J., Yasuda, K., and Kanno, Y.: Transepiphyseal plate osteotomy for severe tibia vara in children: Follow-up study of four cases. J. Pediatr. Orthop. 6:61, 1986.

20. Tachdjian, M. O.: Pediatric Orthopaedics. Philadelphia, W. B. Saunders, 1972, pp. 1462-1468, 1588.

21. Zavijalov, P. V., and Plaskin, J. T.: Elongation of crural bones in children using a method of distraction epiphysiolysis. Vestn. Khir. 103:67, 1967.

22. Zavijalov, P. V., and Plaskin, J. T.: Distraction epiphysiolysis in lengthening of the lower extremity in children. Khirurgiia 44:121, 1968. 


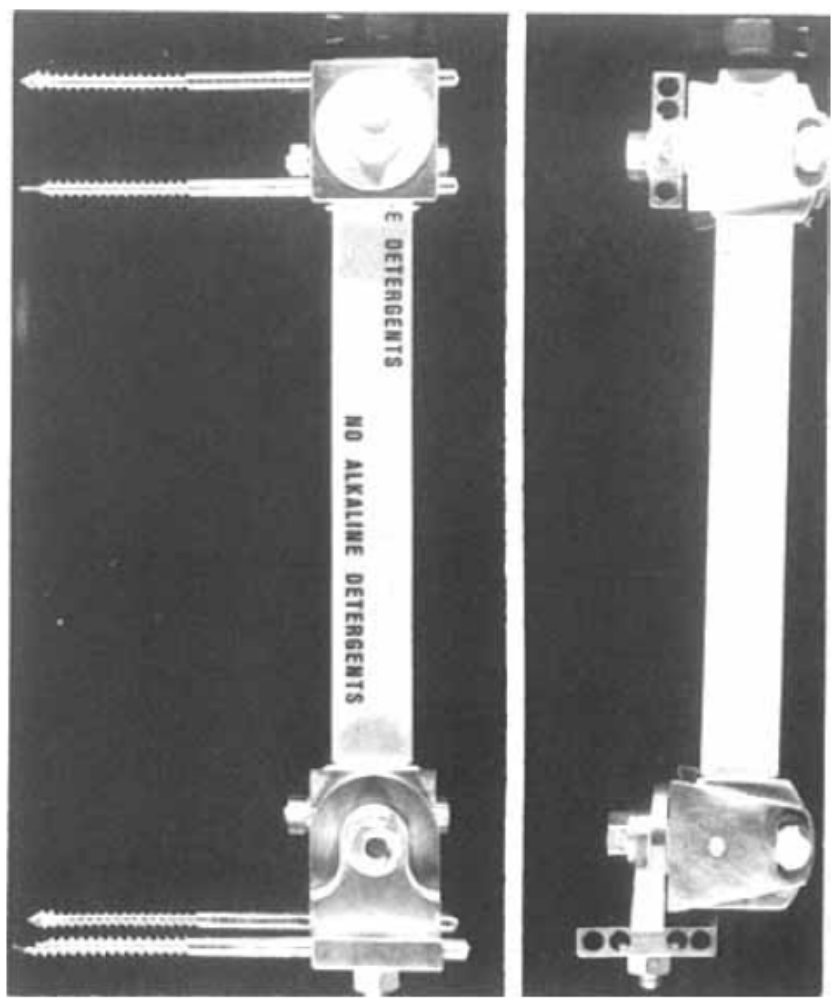

Fig. 1. Modified Wagner apparatus.

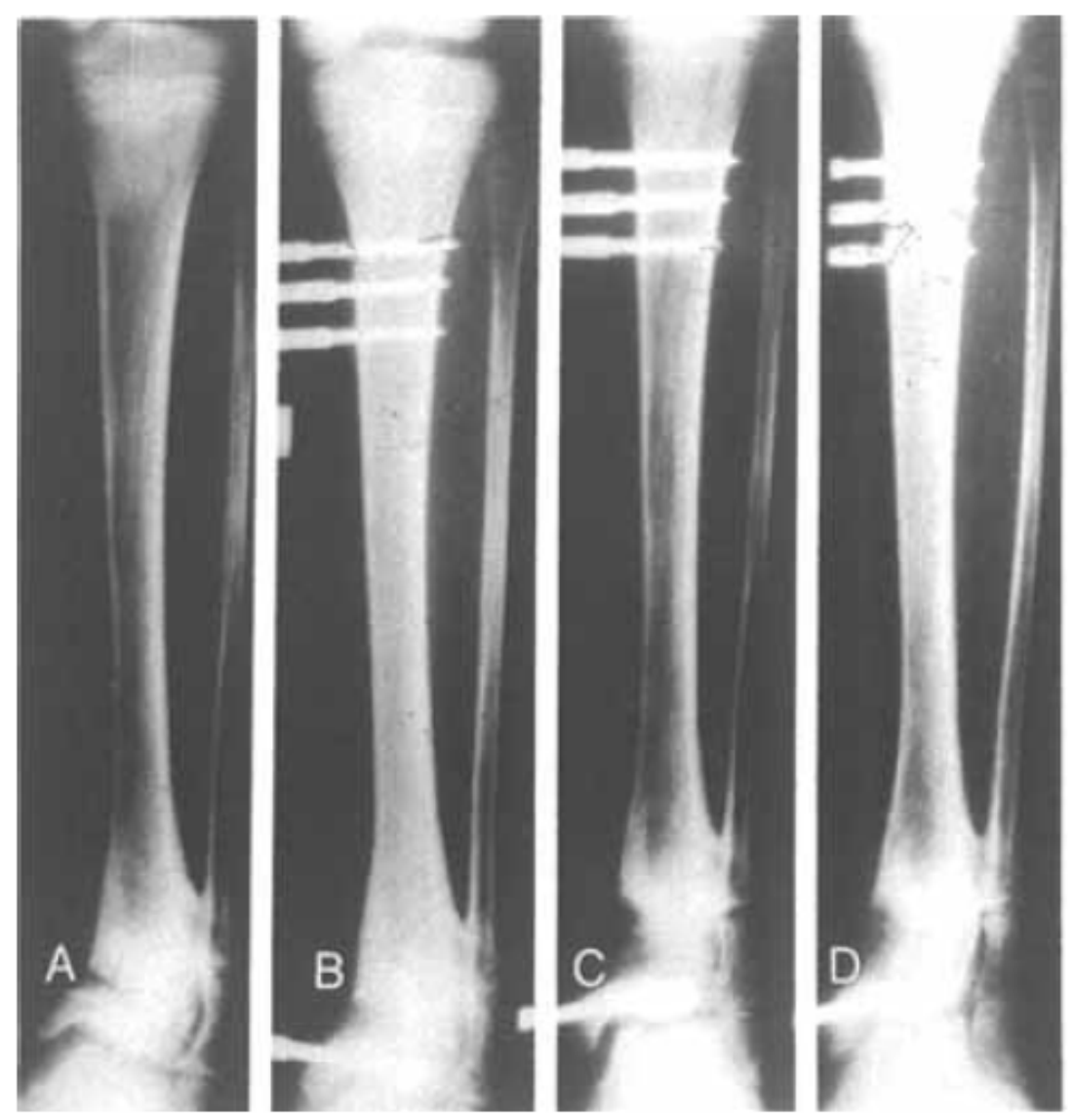

Figs. 2A-2D. Correction according to Strategy I. (A) Preoperative roentgenograph. Roentgenographs (B) 20, (C) 60, and (D) 90 days after operation. 


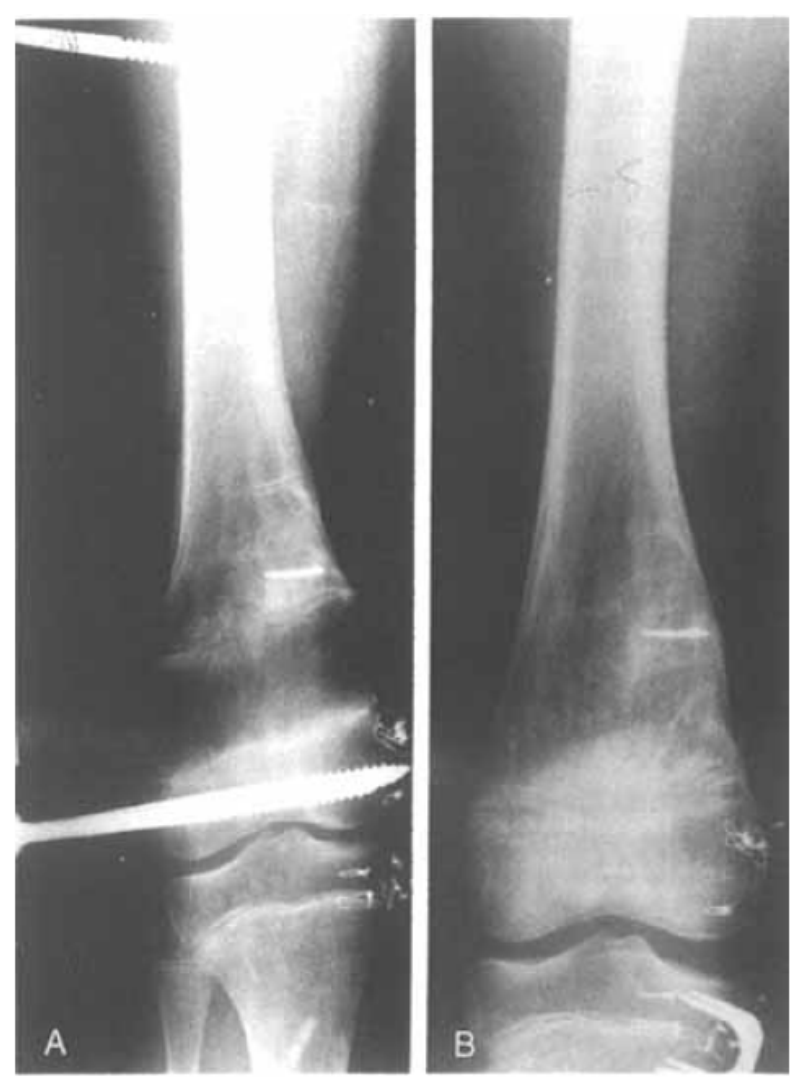

Figs. 3A and 3B. Correction by Strategy II. Bony bridge. (A) Sixty days after operation. Lengthening, $5.5 \mathrm{~cm}$. (B) Nine months after operation.
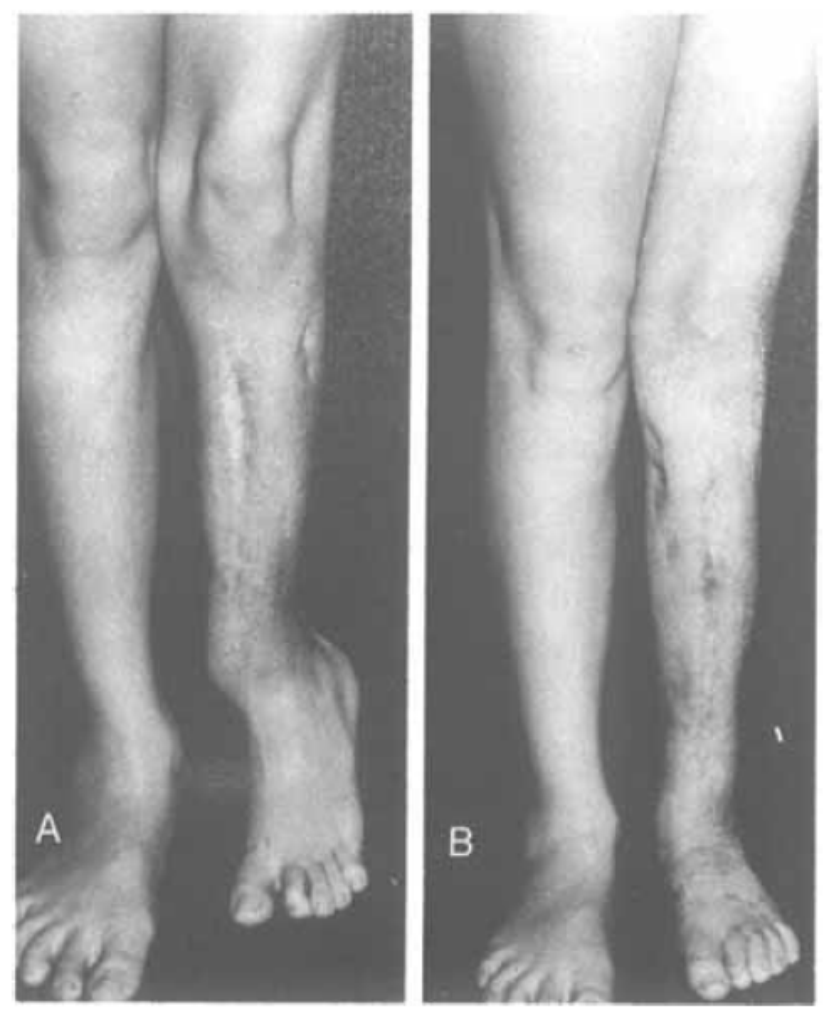

Figs. 4A and 4B. Previous congenital pseudoarthritis. Distal tibia valgus. Absence of bony bridge. (A) Clinical view preoperatively. (B) Clinical view six months after operation. 


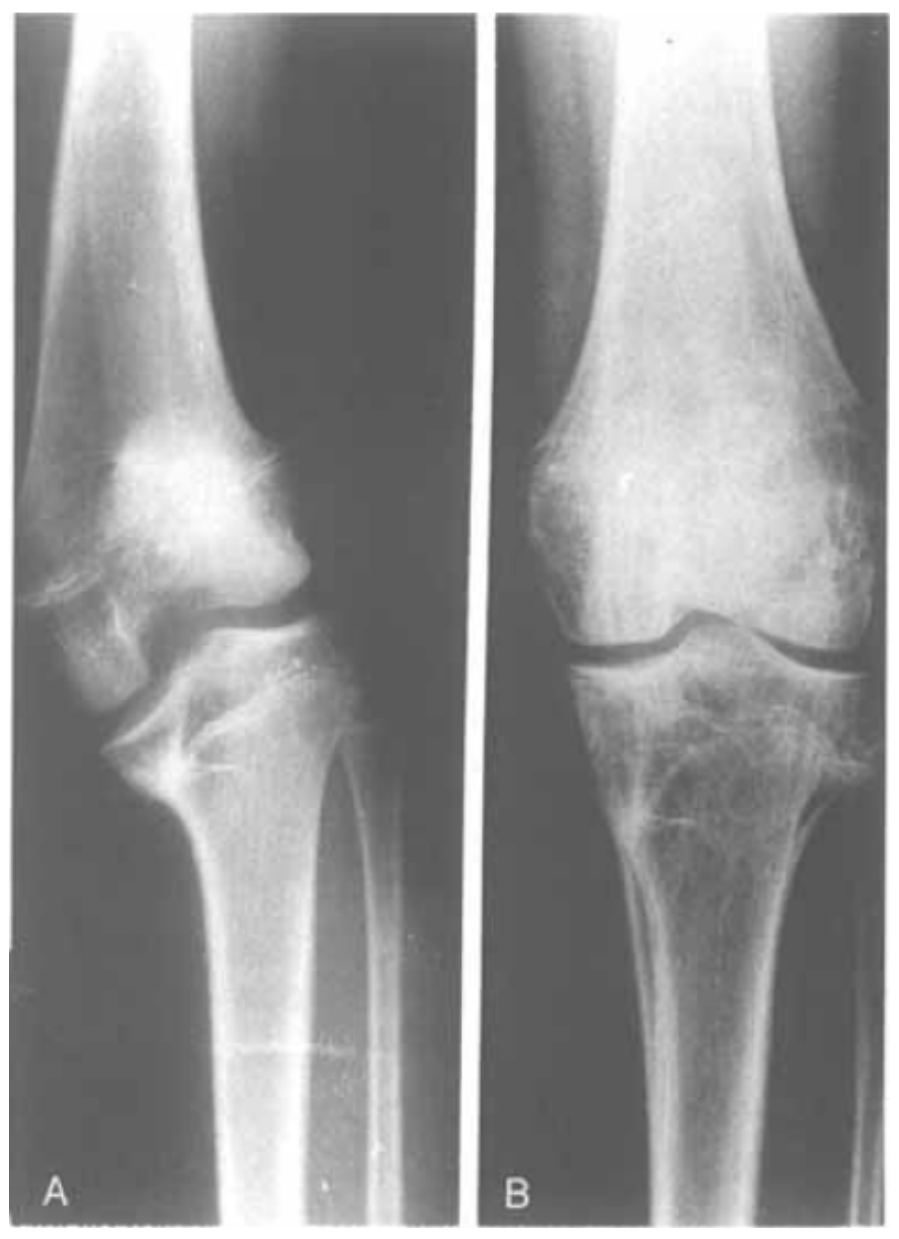

Figs. 5A and 5B. Roentgenograph of the distal femur valgus and proximal tibia varus with physeal bony bridges caused by previous infection due to Meningococcus. (A) Preoperative period. (B) One year after operation. 


\begin{tabular}{|c|c|c|c|c|c|c|c|}
\hline \multicolumn{8}{|c|}{ Table 1. Clinical Profile of Patients } \\
\hline $\begin{array}{c}\text { Bony } \\
\text { Bridge }\end{array}$ & $\begin{array}{c}\text { Follow-Up } \\
\text { Period } \\
\text { (months) }\end{array}$ & Location & Deformity & $\begin{array}{c}\text { Shortening } \\
(\mathrm{cm})\end{array}$ & Etiology & Strategy & Lengthening \\
\hline No & 42 & $\begin{array}{l}\text { Distal } \\
\text { femur }\end{array}$ & $22^{\circ}$ valgus & 18 & Congenital & II & $9 \mathrm{~cm}$ \\
\hline No & 36 & $\begin{array}{l}\text { Distal } \\
\text { femur }\end{array}$ & $18^{\circ}$ valgus & 8 & Congenital & II & Complete \\
\hline No & 30 & $\begin{array}{l}\text { Distal } \\
\text { femur }\end{array}$ & $16^{\circ}$ valgus & 15 & Congenital & II & $2.5 \mathrm{~cm}$ \\
\hline No & 18 & $\begin{array}{l}\text { Distal } \\
\text { femur }\end{array}$ & $20^{\circ}$ valgus & & Idiopathic & II & \\
\hline No & 18 & $\begin{array}{l}\text { Distal } \\
\text { femur }\end{array}$ & $20^{\circ}$ valgus & & Idiopathic & II & \\
\hline No & 25 & $\begin{array}{l}\text { Distal } \\
\text { femur }\end{array}$ & $14^{\circ}$ varus & & Traumatic & II & \\
\hline No & 40 & $\begin{array}{l}\text { Distal } \\
\text { femur }\end{array}$ & $25^{\circ}$ valgus & 5.5 & Burn & I & Complete \\
\hline No & 12 & $\begin{array}{c}\text { Proximal } \\
\text { tibia }\end{array}$ & $16^{\circ}$ varus & & Idiopathic & I & \\
\hline No & 12 & $\begin{array}{c}\text { Proximal } \\
\text { tibia }\end{array}$ & $16^{\circ}$ varus & & Idiopathic & I & \\
\hline No & 48 & Distal tibia & $28^{\circ}$ varus & & Traumatic & II & \\
\hline No & 38 & Distal tibia & $14^{\circ}$ valgus & 4 & Congenital & II & Complete \\
\hline No & 38 & Distal tibia & $31^{\circ}$ valgus & 4.5 & Congenital & II & Complete \\
\hline Yes & 20 & $\begin{array}{l}\text { Distal } \\
\text { femur }\end{array}$ & $20^{\circ}$ valgus & 6 & $\begin{array}{c}\text { Septic } \\
\text { arthritis }\end{array}$ & II & $5 \mathrm{~cm}$ \\
\hline Yes & 46 & $\begin{array}{l}\text { Distal } \\
\text { femur }\end{array}$ & $12^{\circ}$ varus & 8 & Traumatic & II & $5.5 \mathrm{~cm}$ \\
\hline Yes & 54 & $\begin{array}{l}\text { Distal } \\
\text { femur }\end{array}$ & $30^{\circ}$ valgus & & Meningitis & I & \\
\hline Yes & 51 & $\begin{array}{c}\text { Proximal } \\
\text { tibia }\end{array}$ & $32^{\circ}$ varus & & Meningitis & I & \\
\hline Yes & 15 & $\begin{array}{l}\text { Proximal } \\
\text { tibia }\end{array}$ & $28^{\circ}$ varus & & Meningitis & II & \\
\hline Yes & 20 & $\begin{array}{c}\text { Proximal } \\
\text { tibia }\end{array}$ & $13^{\circ}$ varus & & Traumatic & $\mathrm{I}$ & \\
\hline Yes & 28 & Distal tibia & $31^{\circ}$ varus & & Meningitis & I & \\
\hline Yes & 11 & Distal tibia & $23^{\circ}$ valgus & 3 & Traumatic & II & Complete \\
\hline
\end{tabular}

